\title{
Intestinal permeability
}

\author{
I Bjarnason
}

\begin{abstract}
Damage to the mucosal barrier may be assessed, non-invasively by use of sugar probes, which permeate through the transcellular or paracellular (tight junction) routes. A standardised test, with analysis of a five hour urine collection has proved useful in studying the sequelae of non-steroid anti-inflammatory drug (NSAID) administration, untreated coeliac disease, and enteric infections. Choice of probe molecule is crucial and lactulose/l-rhamnose seem to be satisfactory, in contrast with polyethylene glycol. Significant correlations have been seen between permeability and plasma IgA concentrates in nephropathy, and between permeability and the passage of neutrophil chemotactic agents. The increased permeability associated with NSAID treatment may relate to the adverse effects of NSAIDs on enterocyte mitochondrial morphology and metabolism. These two factors may predispose the mucosa to permeation of bacterial chemoattractant molecules that elaborate a local inflammatory response. A similar mechanism may operate in patients with untreated Crohn's disease, who show abnormally high permeability. Remission induced by treatment with elemental diets coincides with a reduction in permeability. The period to relapse correlated with the inability of patients to maintain low permeability to sugar probes. These results suggest a mechanism for the benefits of elemental enteral nutrients in the treatment of Crohn's disease.

(Gut 1994; supplement 1: S18-S22)
\end{abstract}

The pathogenesis of many small intestinal diseases entails interaction between changed intestinal permeability, luminal aggressive factors, and mucosal defence mechanisms. ${ }^{1-3}$ Each of these factors can be implicated primarily in the pathogenesis of disease. For instance, non-steroidal anti-inflammatory drugs (NSAIDs) seem to cause specific damage to enterocytes, which leads to increased intestinal permeability. This in turn may increase mucosal exposure to normal luminal contents, resulting in neutrophil chemotaxis and hence inflammation (NSAID enteropathy) in about $65 \%$ of patients receiving these drugs in the long term. ${ }^{4-12} \mathrm{~A}$ variety of endogenous (after bypass surgery) and exogenous microbes (Salmonella, Shigella, Campylobacter, Giardia, and Yersinia) may overwhelm the mucosal defence with resulting low grade neutrophil chemotaxis and increased intestinal per-

meability. ${ }^{13-15}$ Similarly, reduced mucosal defence in both hypogammaglobulinaemia ${ }^{16-19}$ and HIV infection (unpublished data) leads to an enteropathy, which is of similar severity to that seen in NSAID enteropathy.

The study of intestinal permeability has been confounded by technical complexities of test marker analysis, perceived non-specificity of results, and the dilemma that a test induced breach in mucosal integrity may lead to pathogenesis. This is perhaps an understandable situation as the tests have, by and large, been advocated primarily for the purpose of screening for small intestinal disease, ${ }^{20-22}$ and there is a hangover from the golden era of the absorption tests (D-xylose, 3-o-methyl-D-glucose etc), when the test results had no pathogenic implications.

\section{Testing for increased permeability}

The test markers in common use (PEG 400, lactulose, L-rhamnose-mannitol, ${ }^{51} \mathrm{CrEDTA}$ ${ }^{99 \mathrm{~m} T c D T P A}$ ) can be analysed precisely and accurately, but apart from the radiolabelled chelates, these analyses are time consuming and tedious. ${ }^{23-29}$

Tests of intestinal permeability were specifically designed to test intestinal barrier function. Because it seemed probable that they would provide a more sensitive indicator of intestinal disease than absorption, 22-24 methods of assessing the intactness of the intestinal barrier were designed. Initially lactulose, which resists degradation by intestinal disaccharidases, was used by itself to test barrier function. While less than $0.5 \%$ lactulose was excreted in 5 hour urine samples after oral administration, there was a rather low discrimination between normal subjects and patients with coeliac disease. ${ }^{21}$ Fortuitously, it was found that rendering the test solution hyperosmolar $(1500 \mathrm{mmol} / \mathrm{l}$, with a readily absorbed osmotic filler) increased the urine excretion of lactulose only marginally in normal subjects, but greatly in patients with coeliac disease, thereby offering good discrimination between the two groups. ${ }^{21}$

Urinary excretion of a single dose of a test substance is dependent on a number of factors other than mucosal integrity (Figure), which not only reduce the sensitivity and specificity of the test procedure, but also pose a problem of interpretation of test results. To overcome these problems, Menzies formulated the principle of differential urinary excretion of orally given test substances. The Figure details the intestinal process of two such test substances). ${ }^{22}$ Any variation in pre or postmucosal determinants of the sugars' overall permeation will affect the two test probes equally, so that their urinary excretion ratio

Biochemistry, King's College School of

Medicine and Road, London SE5 9PJ.
} 
Completeness of ingestion

F Gastric dilution

Gastric emptying

Intestinal dilution

Intestinal transit

Bacterial degradation

Fु Brush border hydrolysis

Permeation pathway

Blood flow

Endogenous production

Oetabolism

Tissue distribution

Mode of renal excretion

2 Completeness of urine collection

The urine excretion of a permeability marker given orally is dependent on a variety of pre and postmucosal factors as well as intestinal permeability. When two test substances are given together, however, the emphasis is not on the absolute amounts excreted but their ratio (lactulosel L-rhamnose) as the ratio is independent of nonpermeability factors. For instance an accelerated intestinal transit will reduce the amount of lactulose in urine. The amount of L-rhamnose will be equally reduced so that their ratio (\% dose) will not change.

(\% of the orally administered test dose) is not affected. The di monosaccharide urinary excretion ratio then becomes a specific measure of intestinal permeability. ${ }^{51} \mathrm{CrEDTA}$ can be substituted for the disaccharide, but the urine collection should be no longer than five hours, as intestinal degradation of the monosaccharide by bacteria may become important.

The use of PEG 400 has posed a particular problem for intestinal permeability workers since its introduction in $1977 .{ }^{30}$ The main anomaly is that $20-50 \%$ of an orally given test dose is excreted in five hour urine samples, while only $0 \cdot 5-1 \cdot 1 \%$ of lactulose or ${ }^{51} \mathrm{CrEDTA}$ is excreted during that time. ${ }^{28}$ This occurs despite similarities in their molecular size, weight, water solubility, and physiochemical properties. $^{31}$ Probe molecular geometry does not seem to be important in this respect. ${ }^{32}$ The completeness of the urine excretion of PEG 400 after intravenous administration is low and variable. ${ }^{28}$ The results obtained with PEG 400 in disease and its behaviour after hyperosmolar stress and detergent are all in keeping with a transcellular permeation pathway. It is difficult to visualise how such a readily absorbed test probe could be a useful means of assessing a barrier function. Moreover, various polymers of PEG all permeate by the same route, so PEG does not conform to the principle of the differential urinary excretion of orally given test substances. This non-conformity leads to reservations about the use of PEG and interpretation of PEG test results. ${ }^{33}$ Furthermore, the apparent increased intestinal permeation of PEG 400 in patients with Crohn's disease and their first degree relatives, (the main impetus for the test's revival) has not been substantiated. ${ }^{29} 3435$

\section{Consequences of increased intestinal permeability}

The immediate consequences of increased intestinal permeability have not been extensively studied. Increased intestinal permeability may permit mucosal exposure to luminal antigens, with implications for the pathogenesis of both local and systemic diseases. The possibility that increased intestinal permeability can lead to systemic disease such as ankylosing spondylitis, by the mechanism of molecular mimicry is, in particular, controversial. ${ }^{36-40}$

There are three studies that suggest that increased intestinal permeability to these small probes (approximately 340 Daltons) may reflect increased macromolecular permeation. Davin et al found a significant correlation between intestinal permeation of ${ }^{51} \mathrm{CrEDTA}$ and IgA immune complex plasma concentrations in patients with IgA associated nephropathies. ${ }^{41}$ Ramage et al showed a significant correlation between the permeation of ${ }^{51}$ CrEDTA and ovalbumin in rats infected with Nippostrongylus brasiliensis. ${ }^{42}$ Finally, there was a significant correlation between the permeation of the neutrophil chemotactic bacterial product $\mathrm{N}$-formyl-methonyl-leucylphenyl-alanine (analogue) and ${ }^{51}$ CrEDTA in rats treated with dithiothreitol. ${ }^{43}$ While this establishes a link between macromolecular permeation and the results of the test probes, it should be remembered that macromolecular permeation is also governed by lipid solubility (transcellular permeation), concentration (determined by rate of degradation in part), and the local and systemic immune defence mechanisms.

\section{Intestinal permeability in disease}

A number of environmental factors or disease states may increase intestinal permeability. At least two situations - NSAID enteropathy and Crohn's disease - have contributed substantially to the current understanding of intestinal pathophysiology by permeability studies linked with other new investigational approaches assessing small intestinal function.

\section{NSAID ENTEROPATHY}

NSAID enteropathy is the prototype of a small intestinal disease caused mainly by an action of this drug class in disrupting the intestinal barrier with secondary, unavoidable inflammatory changes brought about by an imbalance between luminal aggressive factors and mucosal defence.

In rats, the first sign of NSAID toxicity is evident within one hour of NSAID administration in the form of uncoupling of enterocyte mitochondrial oxidative phosphorylation. ${ }^{10-12}$ At five hours, before macroscopic damage is evident, there are considerable increases in the activities of succinate dehydrogenase and citrate synthase (TCA enzymes), which are indeed unexpected in light of possible mitochondrial damage. Further studies, however, using activity stains on frozen tissue section confirm that there is up regulation of mitochondrial enzyme activities both in the TCA cycle and the respiratory chain. This response to mitochondrial damage may be appropriate but the direct consequence of uncoupling is a drop in the production of ATP with loss of regulatory control of the intracellular junctions. Human evince this loss as increased 
intestinal permeability to ${ }^{51} \mathrm{CrEDTA}$ within 12 hours of receiving NSAID. Increased intestinal permeability is not seen with pro NSAIDs and, curiously enough, is also not seen when indomethacin is given with glucose and citrate. ${ }^{4445}$ The precise role of reduced mucosal prostaglandins is uncertain, but as the main action of prostaglandins is reparative (increased mucous production, increased blood flow, and re-epithelisation), the main consequence of inhibiting cyclo-oxygenase may be to prolong the permeability changes compared with causing them.

Once intestinal permeability is increased for prolonged periods of time, the sequence of events are predetermined. The mucosa is exposed to luminal aggressive factors (in the small intestine, mainly bile, pancreas secretion, bacteria, and their degradation products), of which bile is particularly well reported in NSAID enteropathy. ${ }^{46-49}$ It is only when a neutrophil chemoattractant gains access to the mucosa that there is macroscopic damage. ${ }^{50-55}$ In humans, there is overwhelming evidence that the main neutrophil chemoattractant is a metronidazole sensitive microbe which may indeed be part of the normal intestinal flora. ${ }^{53}$ Once the neutrophils are activated by contact with the chemoattractant, they cause damage to their immediate surroundings by generation of oxygen reactive species and lysosomal enzyme release. ${ }^{54-56}$ When this occurs within the mucosa, tissue damage is unavoidable and leads to the complications of NSAID enteropathy, namely, blood and protein loss. ${ }^{8} 10$ Thus, NSAIDs have a specific biochemical action on the enterocyte, resulting in increased intestinal permeability which, in turn, leads to a non-specific tissue reaction of NSAID enteropathy.

There are other agents that may damage the small intestine by a similar mechanism. Chemotherapeutic agents, chronic alcohol consumption, diabetes, and radiation all increase small intestinal permeability, but an enteropathy has not yet been sought. ${ }^{57-63}$

\section{CROHN'S DISEASE}

Intestinal permeability is almost invariably increased in patients with Crohn's disease. ${ }^{64-69}$ There are, however, important difficulties relating permeability changes to disease activity. No universal 'method of choice' has been accepted for assessing disease activity, and permeability changes seem related both to disease activity and severity. Clinical disease activity scores have probably been the single most important factor hindering the development of reliable objective indices of disease activity. Where such techniques exist for assessing activity scores (faecal excretion of indium-111 labelled neutrophils), widespread acceptance has not been forthcoming, possibly because of the investigator effort such techniques require.

Although increased intestinal permeability has long been implicated in the pathogenesis of inflammatory bowel disease, there is no proof of this relation. There is, however, new and interesting evidence to suggest that the clinical relapse of Crohn's disease may be mediated by increased intestinal permeability with an identical sequence of events to that seen in the tissue phase of NSAID enteropathy. ${ }^{3}$

A number of studies show the effectiveness of the treatment of acute Crohn's disease with elemental diet as the sole course of nutrition. ${ }^{70-73}$ Of more than 100 patients treated at a single centre, $85 \%$ achieved clinical remission, usually within a week of starting treatment. ${ }^{74}$ The more distal the disease, the longer the response time. Treatment with elemental diet is as effective as total parenteral nutrition and corticosteroids, but there are important problems with the diet's high cost, poor palatability, and post-treatment relapse rates. The method of assessing the diet's effectiveness is, however, suspect because it uses highly subjective clinical disease activity scores, which will indeed improve simply by starving the patient. We therefore assessed whether treatment with elemental diet was more than a symptomatic form of treatment or whether there was evidence of functional improvement.

A large group of patients with Crohn's disease had variable combined assessments including those of nutritional states, intestinal permeability, and inflammation (indium-111 leucocyte faecal excretions), and soluble interleukin 2 receptor values (an index of $T$ cell activation) pretreatment and two, and four to six weeks after treatment. ${ }^{75} 76$ Briefly, most of the nutritional indices did not change significantly. Intestinal permeability and inflammation were significantly and drastically reduced, but interleukin 2 soluble receptor values remained raised and unchanged. Interestingly and significantly, those patients with normal intestinal permeability after treatment had consistently long ( $>$ six months) remissions from acute disease, while those with increased intestinal permeability relapsed within six months. These results equate disease activity with increased intestinal permeability and acute inflammation. These aspects of the disease respond to treatment with elemental diets, whose main action is shown not to entail the provision of adequate calories or nutrition. (Most patients initially lost weight during treatment, which rarely provides more than $2800 \mathrm{kcal} /$ day when taken orally).

Elemental diet, however, drastically changes luminal aggressive factors. Along with the fact that the causes of relapse of Crohn's disease (NSAIDs, intestinal infections, alcohol binges, stress) all increase or have the potential to increase intestinal permeability, ${ }^{13} 14$ 77-85 these data suggest that the intestinal permeability barrier is of crucial importance for initiating relapse, permitting mucosal exposure of luminal antigen, eliciting neutrophil chemotaxis and hence, for being unwell. These factors would be identical to those proposed in the second stage framework for NSAID enteropathy. Indeed, there is considerable evidence that the immune system is recognising intestinal flora in Crohn's disease. Neutrophils have increased formyl-methionylleucyl-phenylalanine surface receptors in acute 
Crohn's disease: ${ }^{86} 87$ Macpherson et al (unpublished data) have isolated mucosal IgG from patients with Crohn's disease, and these IgG not only relate quantitatively to disease activity but are predominantly directed towards normal intestinal flora. The neutrophil flux to the intestine is, however, 10 times greater than that seen in NSAID, hypogammaglobulinaemic, and HIV enteropathy, as well as that seen in infectious enteritis. Thus the main problem in Crohn's disease may be the unchecked neutrophil response to common luminal substances. The main cause of the disease will probably not include the neutrophils themselves, but the persistent $T$ cell activation may be a clue showing where to look.

1 Bjarnason I. Intestinal permeability barriers. In: Peters TJ, ed. The cell biology of inflammation in the gastrointestinal tract. Hull: Corners Publication, 1990: 127-42.

2 Bjarnason I. Non-steroidal anti-inflammatory drug induced small intestinal inflammation in man. In: Pounder R, ed. Recent advances in gastroenterology-7 London: Churchill Recent advances in gastroente

3 Bjarnason I, Macpherson AJS, Teahon K. Nonsteroidal anti-inflammatory drugs and inflammatory bowel disease. Can f Gastroenterol 1993; 7: 160-9.

4 Bjarnason I, Williams P, So A, Zanelli G, Lev AJ, Gumpel $\mathrm{MJ}$, et al. Intestinal inflammation and permeability in rheumatoid arthritis; effects of non-steroidal antiinflammatory drug. Lancet 1984 ; ii: 1171-4.

5 Bjarnason I, Zanelli G, Smith T, Prouse P, De Lacey G, Gumpel MJ, et al. Nonsteroidal anti-inflammatory drug induced inflammation in humans. Gastroenterology 1987; 93: 480-9.

6 Bjarnason I, Macpherson A. The changing gastrointestinal side effect profile of non-steroidal anti-inflammatory side effect profile of non-steroidal anti-inflammatory drugs. A new approach for the prevention of a new
problem. Scand $\mathcal{f}$ Gastroenterol 1989; 24 (suppl 163): problem.

7 Bjarnason I, Smethurst P, Hayllar J, Levi AJ. NSAID enteropathy; the main site of chronic blood loss in patients on NSAIDs. Gut 1900; 91: A1203.

8 Morris J, Madhok R, Sturrock RD, Capell HA, Mackenzie JF. Enteroscopic diagnosis of smal bowel ulceration in patients receiving non steroidal anti-inflammatory drugs. Lancet 1991; 337: 520.

9 Bjarnason I, Zanelli G, Prouse P, Smethurst P, Smith T, Levi $S$, et al. Blood and protein loss via small intestinal inflammation induced by non-steroidal anti-inflammatory inflammation induced by non- 1987 ; ii: $711-4$.

10 Lang J, Price AB, Levi AJ, Burk M, Gumpel JM, Bjarnason I. Diaphragm disease: the pathology of non-steroidal antiinflammatory drug induced small intestinal structures, $\mathcal{F}$ Clin Pathol 1988; 41: 516-26.

11 Hayllar J, Somasundaram S, Sarathchandra P, Levi AJ, Bjarnason I. Early cellular events in the pathogenesis of NSAID enteropathy in the rate. Gastroenterology 1991; 100: A216.

12 Somasundaram S, Macpherson AJ, Hayllar J, Saratchandra $\mathrm{P}$, Bjarnason I. Enterocyte mitochondrial damage due to NSAID in the rat. Gut 1992; 33 (suppl): S5.

13 Noone C, Menzies IS, Banatvala JE, Scopes JW. Intestinal permeability and lactose hydrolysis in human rotaviral permeability and lactose hydrolysis in human rotaviral gastroenteritis assessed simulatneously by non-invasive
differential sugar permeation. Eur f Clin Invest 1986; 6: 217-25.

14 Parrili G, Cuomo R, Nardone G, Maio G, Izzo CM, Budillon $G$. Investigation of intestinal function during acute viral hepatitis using combined sugar oral loads. Gut 1987; 28: 1439-44

15 Kordossis T, Joseph AEA, Gane JN, Bridges CE, Griffin GE. Fecal leukocytosis, indium-111-labelled autologous polymorphonuclear leucocyte abdominal scanning, and quantitative fecal indium-111 excretion in acute gastroenteritis and enteropathogen carriage. Dig Dis Sci 1988; 33: 1383-90.

16 Ament ME, Ochs HD, Davis SD. Structure and function of the gastrointestinal tract in primary immunodeficiency syndromes. A study of 39 patients. Medicine 1973; 52: $227-48$.

17 Johnson RL, Van-Arsdel PP, Tobe AD, Ching Y. Adult hypogammaglobulinaemia with malabsorption and iron deficiency anaemia. Am f Med 1967; 43: 935-43.

18 Diaz-Buxo JA, Hermans PE, Huizenga KA. Gastrointestinal dysfunction in immunoglobulin deficiency. Effects of corticosteroid and tetracyclin. $\mathcal{F} A M A$ 1975; 233: 1189-91.

19 Teahon K, Webster D, Price AB, Bjarnason I. Studies of gastrointestinal structure and function in patients with primary hypogammaglobulinaemia. Gut (in press).

20 Menzies IS. Medical importance of sugars in the alimentary tract. In: Grenby TH, Parker KJ, Lindley MJ, eds. Developments in sweeteners-2 London: Applied Science, 1983: 89-117.
21 Menzies IS. Absorption of intact oligosaccharide in health and disease. Biochem Soc Trans 1974; 2: 1042-7.

22 Menzies IS. Transmucosal passage of inert molecules in health and disease. Skadhauge E, Heintze $\mathrm{K}$, eds. Intestinal absorption and secretion. Falk Symposium 36, Lancaster: MTP Press, 1984: 527-43.

23 Cooper BT. The small intestinal barrier. In: Losowsky $\mathrm{Hm}$, Heatley RV, eds. Gut defences in clinical practice. Edinburgh: Churchill Livingstone, 1986: 117-32.

24 Hamilton I. Small intestinal permeability. In: Pounder RE, ed. Recent advances in gastroenterology-6. Edinburgh: Churchill Livingstone, 1986: 73-91.

25 Menzies IS. Quantitative estimation of sugars in blood and urine by paper chromatography using direct densitometry. F Chromatogr 1973; 81: 109-27.

26 Menzies IS, Mount NJ, Wheeler MJ. Quantitative estimation of clinically important monosaccharides in plasma by rapid thin layer chromatography. Ann Clin Biochem 1978; 15: $65-76$.

27 Menzies IS, Seakins JWT. Sugars. In: Smith I, Jenkins JWT, eds. Chromatographis and electrophorectic techniques. vol 1. London: Wm Heineman 1976: 183-217.

28 Maxton DG, Bjarnason I, Reynolds AP, et al. Lactulose, 51 $\mathrm{Cr}$ labelled ethylenediaminetetraacetate, L-rhamnose and polyethylene glycol 400 as probe markers for assessment polyethylene glycol 400 as probe markers for assessment in vivo of

29 Teahon K, Smethurst P, Levi AJ, Menzies IS, Bjarnason I. Intestinal permeability in patients Crohn's disease and their first degree relatives. Gut 1992; 33: 320-3.

30 Chadwick VS, Phillips SF, Hoffman AF. Measurement of intestinal permeability using low molecular weight polyethylene glycols. Gastroenterology 1977; 73: 241-51.

31 Hollander D, Ricketts D, Boyd CAR. Importance of probe molecular geometry in determining intestinal permeability. Can $\mathcal{F}$ Gastroenterol 1988; 2 (supl A): 35-8A.

32 Teahon K, Menzies IS, Bjarnason I. Importance of molecular geometry on permeation rates of in vivo permemolecular geometry on permeation rates of

33 Peters TJ, Bjarnason I. Uses and abuses of intestinal permeability measurements. Can $\mathcal{f}$ Gastroenterol 1988; 2: 127-32.

34 Hollander D. Crohn's disease - a permeability disorder of tight junctions. Gut 1988; 29: 1621-4.

35 Hollander D, Vadheim CM, Breththotz E, Peterson GM, Delahunty TJ, Rutter J. Increased intestinal permeability in Crohn's disease patients and their first degree relatives: an etiologic factor? Ann Intern Med 1986; 105: 883-5.

36 Zaphiropoulos GC. Rheumatoid arthritis and the gut. $\mathrm{Br} \mathcal{F}$ Rheumatol 1986; 15: 138-9.

37 Bjarnason I, Peters TJ. Helping the mucosa make sense of macromolecules. Gut 1987; 28: 1057-61.

38 Prendergast JH, Sullivan JS, Csczy A, Upfold LI, Edmunds $\mathrm{JP}$, Bashir HV, et al. Possible role of enteric organisms in the pathogenesis of ankylosing spondylities and other seronegative arthropathies. Infect Immun 1983; 41: 935-41.

39 Ebringer A. The cross tolerance hypothesis, HLA-B27 and ankylosing spondylitis. Br $\mathcal{F}$ Rheumatol 1983; 22 (suppl 2): $53-6$.

40 Keat A. Reiters syndrome and reactive arthritis in perspective. N Engl f Med 1983; 309: 1605-15.

41 Davin JC, Forget P, Mahieu PR. Increased intestinal permeability to $(51 \mathrm{Cr})$ EDTA is correlated with IgA complex-plasma levels in children with IgA-associated nephropathies. Acta Paediatr Scand 1988; 77: 118-24.

42 Ramage JK, Stanisz A, Scicchitano R, Hunt RH, Perdue $\mathrm{MH}$. Effects of immunologic reaction on rat intestinal epithelium. Correlation of increased intestinal permeability to chromium 51 labelled ethylenediaminetetraacetic acid and ovalbumin during acute inflammation and anaphylaxis. Gastroenterology 1988; 94: 1368-75.

43 Ferry DM, Butt TJ, Broom MF, Hunter J, Chadwick VS. Bacterial chemotactic oligopeptides and the intestinal mucosal barrier. Gastroenterology 1989; 97: 61-7.

44 Biarnason I, Fehily B, Smethurst P, Menzies IS, Levi AI. The importance of local versus systemic effects of NSAID to increase small intestinal permeability in man. Gut 1991; 32: $275-7$.

45 Bjarnason I, Smethurst P, Walker F, Macpherson A McElnay SC, Pearson P, et al. Glucose and citrate reduce the permeability changes caused by indomethacin Gastroenterology 1992; 102: 1546-50.

46 Robert A, Asano T. Resistance of germ free rats to indomethacin-induced intestinal lesions. Prostaglandins 1977; 14: 331-41.

47 Satoh $\mathrm{H}$, Guth PH, Grossman MI Role of bacteria in gastric ulceration produced by indomethacin in the rat: cytoprotective action of antibiotics. Gastroeneterology

48 Del Soldato P, Foschi D, Benoni G, Velo GP. Early and late phases in the formation by anti-inflammatory drugs of intestinal lesions in the rat. In: Rainsford KD, Velo GP, eds. Side effects of antiinflammatory drugs. Lancaster: MTP Press, 1987: 67-81.

49 Brodie DA, Cook PG, Bauer BJ, Dagleg E. Indomethacininduced intestinal lesions in the rat. Toxicol Appl Pharmacol 1970; 17: 615-24.

50 Wallace JL, Keenan CM, Granger DN. Gastric ulceration induced by nonsteroidal antiinflammatory drugs is a neutrophil dependent process. Am f Physiol 1990; 259: G462-7.

51 Wallace JL, Arfors KE, McKnight GW. A monoclonal antibody against the CD 18 leucocyte adhesion molecule 
prevents indomethacin-induced gastric damage in the rabbit. Gastroenterology 1991; 100: 878-83.

52 Granger DN, Benoit JN, Suzuki M, Grisham MB. Leucocyte adherence to venular endothelium during ischemia perfusion. Am 7 Physiol 1985; 257: G683-8.

53 Bjarnason I, Hayllar J, Smethurst P, Price AB, Grumpel MJ. Metronidazole reduces intestinal inflammation and blood loss in non-steroidal anti-inflammatory drug induced enteropathy. Gut 1990; 31: 777-80.

$54 \mathrm{Malech}$ MI, Callin JI. Neutrophils in human disease. $N$ Engl f Med 1987; 317: 687-94

55 Weiss SJ. Tissue destruction by neutrophils. $N$ Engl f Med 1989; 320: 365-76.

56 Segall AW. The electron transport chain of the microbicidal oxidase of phagocytic cells and its involvement in the molecular pathology of chronic granulomatous disease. In: Peters TJ, ed. The cell biology of inflammation in the In: Peters TJ, ed. The cell biology of inflammation in the gastrointestinal tract. Hull: Corners Publication, 1990: $51-73$.

57 Bjarnason I, Ward K, Peters TJ. The leaky gut of alcoholism; a route of entry of toxic compounds. Lancet 1984; i: $179-82$.

58 Cooper BT, Ukabam SO, O'Brian IA, Hare JP, Corrall RJ Intestinal permeability in diabetic diarrhoea. Diabetic Med 1987; 4: 49-52.

59 Sieber GR, Mayer RJ, Levin MJ. Increased gastrointestinal absorption of large molecules in patients after 5fluorouracil therapy for metastatic colon carcinoma Cancer Res 1980; 40: 3430-6.

60 Selby P, McElwain TJ, Crofts M, Lopes N, Mundy J 51EDTA test for intestinal permeability. Lancet 1984; ii: 31.

61 Pearson ADJ, Craft AW, Pledger JV, Eastham EJ, Laker MF, Pearson CS. Small bowel function in acute lymphoblastic leukaemia. Arch Dis Child 1984; 59: $460-5$.

62 Pledger JV, Pearson ADJ, Craft AW, Laker MF, Eastham EJ. Intestinal permeability during chemotherapy fo childhood tumors. Eur $\mathcal{F}$ Pediatr 1988; 147: 123-7.

63 Selby PJ, Lopes N, Mundy J, Crofts M, Millar JL, McElvain TJ. Cyclophosphamide priming reduces intestinal damag in man following high dose melphalan chemotherapy. $\mathrm{Br} \mathcal{F}$ Cancer 1987; 55: 531-3.

64 Bjarnason I, O'Morain C, Levi AJ, Peters TJ. Absorption of 51 chromium-labelled ethylenediaminetetraacetate in inflammatory bowel disease. F Lab Clin Med 1986; 108: inflammatc

65 O'Morain C, Abelow CA, Cheru LR, Fleischner GM, Das KM 51-CrEDTA test: a useful test in the assessment of KM. 51-CrEDTA test: a useful test in the assessment of inflammatc $430-5$.

66 Casellas F, Aguade S, Soriano B, Accarino A, Molero J, Guarner L. Intestinal permeability to $99 \mathrm{mTC}$-diethylenetetriaminopentaacetic acid in inflammatory bowe disease. Clin Invest Med 1988; 81: 767-70.

67 Pironi L, Migliolti M, Ruggeri E, Levorato M, Dallasta MA Corbelli C, et al. Relationship between intestinal permeability to 51 CrEDTA and inflammatory activity in asymptomatic patients with Crohn's disease. Dig Dis $S c i$ 1990; 35: 582-8.

68 Jenkins RT, Ramage JK, Jones DB, Collins SM, Hunt RH. Small bowel and colonic permeability to $51 \mathrm{Cr}$ EDTA in patients with active inflammatory bowel disease. Clin patients with active inflam

69 Resnik RH, Royal H, Marshall W, Barron R, Werth T. Intestinal permeability in gastrointestinal disorders. Use of 99mTc DTPA. Dig Dis Sci 1990; 35: 205-11.
70 Workman EM, Alun-Jones V, Wilson AJ, Hunter JO. Diet in the management of Crohn's disease. Hum Nutr Appl Nutr 1984; 38: 469-73.

71 Alun-Jones V, Workman EM, Freeman AH, Dickinson RJ, Wilson AJ, Hunter JO. Crohn's disease: maintenance of remission by diet. Lancet 1985; i: 177-80.

72 O'Morain C, Segal AW, Levi AJ. Elemental diet as a primary treatment of acute Crohn's disease: a controlled trial. BMF 1984; 288: 1859-62.

73 Alun-Jones V. Comparison of total parenteral nutrition and elemental diet in induction of remission of Crohn's disease. Dig Dis Sci 1987; 32S: 100-7.

74 Teahon K, Smethurst P, Levi AJ, Bjarnason I. Ten years experience with elemental diets in the management of experience with elemental diets in the

75 Teahon K, Smethurst P, Levi AJ, Bjarnson I. The effect of elemental diet on intestinal inflammation and permeability in Crohn's disease. Gastroenterology 1991; 101 84-9.

76 Duane PD, Teahon K, Crabtree JE, Levi AJ, Heatley RV, Bjarnason I. The relationship between nutritional status and serum soluble interleukin 2 receptor concentrations in patients with Crohn's disease treated with elemental diet. Clin Nutr 1991; 10: 222-7.

77 Bjarnason I, Williams P, Smethurst P, Peters TJ, Levi AJ. The effects of NSAID and prostaglandins on the permeability of the human small bowel. Gut 1986; 27: 1292-7.

78 Bjarnason I, Smethurst P, Clarke P, Menzies IS, Levi AJ, Peters TJ. Effect of prostaglandins on indomethacin induced increased intestinal permeability in man. Scand $\mathscr{f}$ Gastroenterol 1989; 29 (suppl 164): 97-103.

79 Bjarnason I, Smethurst P, Fenn CG, Lee CF, Menzies IS Levi AJ. Misoprostol reduces indomethacin induced changes in human small intestinal permeability. Dig Dis Sci 1989; 34: 407-11.

80 Jenkins RT, Rooney PJ, Jones DB, Bienenstock Goodacre RC. Increased intestinal permeability in patients with rheumatoid arthritis: a side effect of oral NSAID therapy? Br f Rheumatol 1987; 26: 103-7.

81 Auer IO, Habscheid W, Hiller S, Gerhards W, Eilles C. Nicht-steroidale antiphlogistika erohen die darmpermeabilitat. Dtsch Med Wochensch 1987; 112: 1032-7.

82 Aabakken C, Osnes M. 51-Cr ethylenediaminetetraacetic acid absorption test. Effects of naproxen, a NSAID. Scand acid absorption test. Effects of nap

83 MacQueen G, Marshall J, Perdue M, Siegel S, Bienenstock J. Pavlovian conditioning of rat mucosal mast cells to secrete rat mast cell protease II. Science 1989; 243 $83-5$.

84 D'Inca $\mathrm{R}$, Ramage J, Hunt $\mathrm{RH}$, Perdue $\mathrm{MH}$. Antigeninduced mucosal damage and restitution in the small intestine of the immunised rat. Int Arch Allergy Appl intestine of the immunised

85 Crowe SE, Sestini P, Perdue MH. Allergenic reactions of rat jejunal mucosa. Gastroenterology 1990; 99: 74-82.

86 Sartor RB. The role of intestinal bacteria in initiation and perpetuation of inflammatory bowel disease. In: Williams $\mathrm{CN}$, ed. Treands in inflammatory bowel disease. Falk Symposium 56. Dordrecht: Kluwer Academic Publishers, 1991: 17-27.

87 Anton PA, Targan SR, Shanahan F. Increased neutrophil receptors for and response to the proinflammatory in Crohn's disease. Gastroenterology 1989; 97: 20-8. 